\title{
Health Centers' Preparedness for Coronavirus (COVID-19) Pandemic in South Wollo Zone, Ethiopia, 2020
}

This article was published in the following Dove Press journal: Risk Management and Healthcare Policy

\section{Fanos Yeshanew Ayele Aregash Abebayehu Zerga (D) Fentaw Tadese (iD}

School of Public Health, College of Medicine and Health Sciences, Wollo University, Dessie, Ethiopia
Correspondence: Aregash Abebayehu Zerga

Email aregusina@gmail.com
Background: COVID-19 is a highly contagious respiratory disease caused by severe acute respiratory syndrome coronavirus two (SARS-CoV-2). Preparedness of health facilities to prevent the spread of COVID-19 is an immediate priority to safeguard patients and healthcare workers and to reduce the spread of the pandemic. However, the preparedness of health centers in south Wollo zone is unknown.

Objective: To assess the preparedness of Health Centers for COVID-19 in South Wollo Zone, Ethiopia, 2020.

Methods: Health facility-based cross-sectional study was conducted among forty-six Health Centers in South Wollo zone in August 2020. The sampled health centers were selected by lottery method. The data was collected from the manager of the health centers using a pretested interviewer-administered and observational checklist. The ReadyScore criteria was used to classify the level of preparedness, in which health centers with a score of $>80 \%$, $40-80 \%$, and $<40 \%$ were considered as better prepared, work to do, and not ready, respectively.

Results: In this study, the median score of health centers preparedness for COVID-19 was $70.3 \pm 21.6$ interquartile ranges with a minimum score of 40.5 and the maximum score of 83.8. Only $12(26.1 \%)$ of the health centers were prepared for the COVID-19 pandemic. The majority $(73.9 \%)$ of the health centers were found within the group of "work to do". Conversely, none of the health centers were found within the "not ready" or below group.

Conclusion: This study concluded that the preparedness status of the majority of health centers in South Wollo Zone was within the "work to do" group. Therefore, the local government and other concerned bodies should monitor and support health centers to increase their preparedness and to build their capacity.

Keywords: COVID-19, preparedness, health centers, South Wollo Zone, Ethiopia

\section{Introduction}

Coronavirus Disease 2019 (COVID-19) is a highly transmittable respiratory disease caused by severe acute respiratory syndrome coronavirus two (SARS-CoV-2). It is transmitted mostly by contact with infectious material that is projected during sneezing or coughing of infected patients. ${ }^{1}$ It has the most common symptoms of fever, dry cough, shortness of breath, and tiredness, and less common symptoms of loss in taste and smell, sore throat, headache, diarrhea, aches, pains, and may progress to pneumonia and respiratory failure. ${ }^{2}$ It was first reported from Wuhan City, China in December 2019 and now spread at alarming rates all over the world. ${ }^{3}$ 
Until October 31, 2020, over 46 million confirmed cases and 1.19 million deaths were reported in the world. ${ }^{4}$ In Africa, since February 14, 2020, when the first case was reported, above 1.8 million cases, and 42,630 deaths were recorded. ${ }^{5}$ In Ethiopia from March 13, when the case was first detected, until October 31, 2020, a total of 95,789 cases and 1, 464 deaths, were reported. ${ }^{6}$

Due to its infection and rapid transmission, the World Health Organization (WHO) was declared a Public Health Emergency of International Concern and characterized it as a pandemic. ${ }^{7}$ In Ethiopia to mitigate the COVID-19 pandemic, the laboratory test, and treatment centers were extended to regions, zones, and district levels. Physical distancing, hand hygiene, and mask-wearing were highly promoted through media by using drama, music, and posters. For physical distancing to be maximally implemented, schools of all levels were closed; religious gatherings were limited and transport across cities was banned.

The prevention measures include heightened surveillance and rapid identification of suspected cases, followed by patient transfer and isolation, rapid diagnosis, tracing, and follow-up of potential contacts. ${ }^{8}$ The ability to control local transmission depends on the application of principles of rapid identification, prevention, and control, followed by patient isolation, rapid diagnosis, and contact tracing. ${ }^{9}$ The WHO has already developed a global COVID-19 strategic preparedness and response plan, which aims to support countries to accelerate the development of their capacity to prevent, detect, and respond to any potential COVID-19 outbreak. ${ }^{10}$ Ethiopia developed the national comprehensive COVID-19 management handbook interim guideline for healthcare settings, healthcare facility COVID-19 preparedness and response protocol and the ministry of health essential care services guideline during COVID-19. ${ }^{11,12}$

The preparedness level of countries or organizations to prevent an emergency was classified using the ReadyScore criteria created by the "resolve to save lives". ${ }^{13}$ The score determines whether a country is prepared to find, stop, and prevent epidemics, using data from the WHO's Joint External Evaluation (JEE). ${ }^{14}$ Based on this criteria, countries are classified into five levels; better prepared (over $80 \%$ ), work to do $(40-80 \%$ ), not ready (under $40 \%$ ), in progress, and unknown. ${ }^{13}$ Before the onset of COVID-19, the preparedness of Ethiopia for an emergency was $52 \%{ }^{14,15}$ This means there is a potential for lives to be lost if a new health threat emerges in the country. The preparedness of health facilities for COVID-19 response is recognized as critical to shift the pandemic. However, after the onset of the COVID-19, quantitative data on the preparedness of health facilities for covid-19 is limited. Even though a study was conducted on health systems adaptability in Ethiopia, it was not published in a peer-reviewed journal and was conducted by including only $9.8 \%$ of the national health centers. ${ }^{16}$ Hence, assessing healthcare facilities' preparedness is a high priority. ${ }^{17}$ Therefore, this study aimed to assess health centers preparedness towards COVID-19 pandemic which helps to prioritize supports to health centers with significant gaps in preparedness.

\section{Methods}

\section{Study Design and Setting}

Health facility-based cross-sectional study design was carried out in August 2020. The study was conducted among the Health centers of South Wollo zone, Amhara Region, Ethiopia. It is one of the 11 Zones of the Amhara regional state of Ethiopia. It is bordered on the south by North Shewa, on the west by East Gojjam, on the northwest by South Gondar, on the north by North Wollo, on the northeast by Afar Region, and on the east by the Oromia special Zone and Argobba special district. Towns and cities in the south Wollo zone include Dessie, Kombolcha, Haik, Wuchale, Akesta, and Mekaneselam and it has 22 districts. The capital city of south Wollo zone is Dessie town which is located $401 \mathrm{~km}$ north of Addis Ababa the capital of Ethiopia. According to zonal health Department data, a total of 135 health centers are found in the zone.

\section{Sample Size and Sampling Technique}

In south Wollo zone, there are 135 health centers. From these, $46(34 \%)$ health centers were selected by lottery method for this study.

\section{Data Collection and Control}

The data was collected from the manager of health centers. A pre-tested interviewer-administered checklist and observation checklist adapted from the WHO and Centers for Disease Control (CDC) was used to collect the data (Appendix 1) $\cdot{ }^{18,19}$ Before the actual data collection, the checklist was pretested on $5 \%$ ( 2 health centers) of the sample size at Oromia special zone, Amhara region. The data was collected using the local language, Amharic by two trained public health officers. The completeness of the 
collected data was checked by the supervisor and the principal investigators.

\section{Operational Definition Preparedness}

A total of 37 (yes or no) questions were used to compute the preparedness. Responses to these questions were summed and converted into percent. Then, based on the ReadyScore criteria of preparedness; health centers were classified as "better prepared" if they scored over $80 \%$, "work to do" if scored 40 to $80 \%$, and "not ready" if scored less than $40 \%{ }^{13}$

\section{Data Management and Analysis}

The collected data were entered into Epi-Data version 3.1 and exported to the Statistical package for social science (SPSS) version 23 for cleaning and analysis. The reliability of the questions was checked by Cronbach's Alpha $(\alpha=0.72)$. The response of individual variables was coded as yes $=1$ and no $=0$ (Appendix 2). To calculate the preparedness of each health center, the response of individual variables was summed and converted into percent. Once the value of preparedness was converted into percent, normality was checked with histogram and it was not normally distributed. Hence, the median \pm interquartile range of preparedness was calculated. To classify health centers based on the ReadyScore criteria, the calculated preparedness percent of each health center was transformed into categories. Descriptive statistics were computed and reported in frequencies and percentiles. Results were presented using tables and texts.

\section{Ethical Consideration}

This study was conducted in accordance with the Declaration of Helsinki. Ethical clearance was obtained from the Institutional Review Committee of Wollo University, College of Medicine and Health Sciences. A permission letter was gained from the South Wollo zone Health Office, Dessie. Informed consent was taken from the manager of each health center after the purpose and objectives of the study had been informed. They were informed that involvement in the study was voluntary. The name of the health centers was not included in the report.

\section{Result}

\section{Description and Preparedness of the Health Centers}

About one third (34.8\%) of the health centers were from the urban area. The median score of preparedness for COVID-19 was $70.3 \pm 21.6$ interquartile ranges, with a minimum and maximum score of 40.5 and 83.8, respectively. When categorized by the ReadyScore cut-offs, only $12(26.1 \%)$ of the health centers were prepared for the pandemic (scored over 80\%). Majority (73.9\%) of the health centers were found within the group of "work to do". Conversely, none of the health centers was found within the "not ready" or below group.

\section{Coordination, Communication, and Reporting System of the Health Centers}

All health centers had Infection Prevention and Control (IPC) focal persons. The majority (91.2\%) and 44 (95.7\%) of health centers had IPC guidelines and emergency response plans for COVID-19, respectively. Above half (78.3\%) of the health centers had a focal person and an emergency committee for COVID-19 (Table 1).

\section{Personal Protective Equipment (PPE) Supplies in the Health Centers}

Above half $28(60.9 \%)$ of the health centers perform PPE inventory at least once a month. Only $10(21.7 \%)$ and 22 $(47.8 \%)$ of the health centers had sufficient quantity and good quality PPE in store. Only the healthcare workers of 16 (34.8\%) health centers had access to gowns, gloves, face masks, and eye protection for conducting physical evaluations of patients with respiratory symptoms (Table 2).

\section{Training, Triage, and Evaluation of Suspected COVID-19 Cases}

All healthcare workers (HCW) who evaluate or treat suspected and confirmed COVID-19 patients were trained in standard and transmission-based precautions of COVID19. The majority 36 (78.3\%) of HCWs and supportive staff were trained in recognition of COVID 19, and 36 (78.3\%) of the health centers had a physical barrier between patients and workers (Table 3). 
Table I Coordination, Communication, and Reporting System of Health Centers in South Wollo Zone, Ethiopia, 2020

\begin{tabular}{|c|c|c|}
\hline Variables & $\begin{array}{c}\text { Yes } \\
\text { Frequency } \\
\text { (\%) }\end{array}$ & $\begin{array}{c}\text { No } \\
\text { Frequency } \\
\text { (\%) }\end{array}$ \\
\hline The facility has an IPC focal person in place & $46(100)$ & - \\
\hline The facility has an IPC guideline & $42(91.3)$ & $4(8.7)$ \\
\hline Training of IPC focal person at least once a year & $22(47.8)$ & $24(52.8)$ \\
\hline The facility has an emergency response plan for COVID-19 & $44(95.7)$ & $2(4.3)$ \\
\hline $\begin{array}{l}\text { The facility has an emergency committee that meets at least every week to discuss planning for and/or } \\
\text { response to COVID-19 }\end{array}$ & $36(78.3)$ & $10(21.7)$ \\
\hline The facility has designated a focal person(s) for COVID-19 cases & $36(78.3)$ & $10(21.7)$ \\
\hline $\begin{array}{l}\text { HCWs have been given phone number(s) for the focal person(s) to report suspected or confirmed COVIDI } 9 \\
\text { cases }\end{array}$ & $38(82.6)$ & $8(17.4)$ \\
\hline $\begin{array}{l}\text { COVID- } 19 \text { focal person(s), facility leadership, and/or emergency committee know public health authorities at } \\
\text { the national or subnational level to report suspected or confirmed COVID-19 cases }\end{array}$ & $38(82.6)$ & $8(17.4)$ \\
\hline $\begin{array}{l}\text { COVID- } 19 \text { focal person(s) and facility leadership know national or sub-national guidance for referring patients } \\
\text { with suspected or confirmed COVID- } 19 .\end{array}$ & $42(91.3)$ & $4(8.7)$ \\
\hline
\end{tabular}

Table 2 Personal Protective Equipment (PPE) Supplies System in Health Centers of South Wollo Zone, Ethiopia, 2020

\begin{tabular}{|c|c|c|}
\hline Variables & $\begin{array}{c}\text { Yes } \\
\text { Frequency } \\
\text { (\%) }\end{array}$ & $\begin{array}{c}\text { No } \\
\text { Frequency } \\
\text { (\%) }\end{array}$ \\
\hline The facility performs an inventory of PPE supply at least once a month & $28(60.9)$ & $18(39.1)$ \\
\hline PPE available in sufficient quantity & $10(21.7)$ & $36(78.3)$ \\
\hline PPE available in good quality & $22(47.8)$ & $24(52.2)$ \\
\hline A person responsible for managing the supply chain for critical IPC supplies has been identified & $36(78.2)$ & $10(21.7)$ \\
\hline Facility leadership knows how to request additional supplies from national or sub-national authorities & $42(91.3)$ & $4(9.7)$ \\
\hline \multicolumn{3}{|l|}{ Additional considerations for supplies in locations with community transmission } \\
\hline The facility has performed an inventory of PPE supplies in the past 7 days & $20(43.5)$ & $26(56.5)$ \\
\hline \multicolumn{3}{|l|}{ The facility has the following supplies in stock in any amount at the time of the assessment } \\
\hline Non-sterile gloves & $34(73.9)$ & $12(26.1)$ \\
\hline Gowns & $16(34.8)$ & $30(65.2)$ \\
\hline Eye protection (face shields or goggles) & $16(34.8)$ & $30(65.2)$ \\
\hline Face masks & $36(78.3)$ & $10(21.7)$ \\
\hline Alcohol-based hand rub & $44(95.5)$ & $2(4.3)$ \\
\hline Soap & $42(91.3)$ & $4(8.7)$ \\
\hline Disinfectants (eg, sodium hypochlorite) & $42(91.3)$ & $4(8.7)$ \\
\hline $\begin{array}{l}\text { HCWs conducting physical evaluations of patients with respiratory symptoms have access to gowns, gloves, } \\
\text { face masks, and eye protection }\end{array}$ & $16(34.8)$ & $30(65.2)$ \\
\hline
\end{tabular}

\section{Discussion}

This study aimed to assess the preparedness and response level of south Wollo zone health centers in confronting the spread of the COVID-19 pandemic. Health centers are nearly in every community and can be the potential area for the transmission of COVID-19 unless a proper prevention system is established. ${ }^{20}$ Preparedness of the healthcare facilities to prevent the transmission of COVID-19 is an 
Table 3 Training, Triage, and Evaluation of Suspected COVID- 19 Cases Among Health Centers of South Wollo Zone, Ethiopia, 2020

\begin{tabular}{|c|c|c|}
\hline Variables & $\begin{array}{l}\text { Yes } \\
\text { Frequency } \\
\text { (\%) }\end{array}$ & $\begin{array}{l}\text { No } \\
\text { Frequency } \\
\text { (\%) }\end{array}$ \\
\hline All HCWs (including clinical and support staff) are trained in recognition of COVID-19 symptoms & $36(78.3)$ & $10(21.7)$ \\
\hline $\begin{array}{l}\text { HCWs who were working in areas evaluating or treating patients with suspected and confirmed COVID-19 } \\
\text { are trained in standard and transmission-based precautions in the context of COVID-19 }\end{array}$ & $46(100)$ & - \\
\hline $\begin{array}{l}\text { The facility is implementing alternative ways for patients seeking care with respiratory symptoms to } \\
\text { communicate before presenting to the facility, such as a telephone. }\end{array}$ & $31(67.4)$ & $15(32.6)$ \\
\hline $\begin{array}{l}\text { Signs or posters directing patients with respiratory symptoms to proceed directly to the registration desk are } \\
\text { posted at all facility entrances }\end{array}$ & $24(52.2)$ & $22(47.8)$ \\
\hline $\begin{array}{l}\text { A physical barrier is in place between staff and patients presenting to the registration desk (for example, } \\
\text { a plastic/glass window or table providing at least I-meter separation) }\end{array}$ & $36(78.3)$ & $10(21.7)$ \\
\hline $\begin{array}{l}\text { The facility has created a separate area for patients presenting with acute respiratory symptoms (the } \\
\text { "respiratory waiting area") }\end{array}$ & $26(56.5)$ & $20(43.5)$ \\
\hline A well ventilated private area available for physical examination of patients with ARS. & $20(43.5)$ & $26(56.5)$ \\
\hline Benches, chairs, or other seating in the respiratory waiting area is separated by at least I meter & $28(60.9)$ & $18(39.1)$ \\
\hline $\begin{array}{l}\text { Functional hand hygiene stations(soap and water) are available near the registration desk and in the respiratory } \\
\text { waiting area }\end{array}$ & $36(78.3)$ & $10(21.7)$ \\
\hline Alcohol-based hand rub easily available & $44(95.7)$ & $2(4.3)$ \\
\hline $\begin{array}{l}\text { Dedicated toilets are available for patients in the respiratory waiting area Single rooms with doors are available } \\
\text { for the physical evaluation of patients with respiratory symptoms }\end{array}$ & - & $46(100)$ \\
\hline COVID- 19 triage and flow chart are available for HCWs evaluating patients in the respiratory waiting area & $26(56.5)$ & $20(43.5)$ \\
\hline Dedicated Person $(\mathrm{HCW})$ at the entry to order patients & $34(73.9)$ & $12(26.1)$ \\
\hline Isolation center available for suspected or confirmed cases of COVID-19 & $36(78.3)$ & $10(21.7)$ \\
\hline
\end{tabular}

immediate priority to safeguard patients and healthcare workers, protect risk groups, reduce the demand for specialized healthcare, and to minimize the spread of the pandemic to other healthcare facilities and the wider community. $^{21}$

In this study, the median preparedness score of the health centers for COVID- 19 was $70.3 \pm 21$.6. It was consistent with the mean score of preprint research conducted on the health systems adaptability at primary level care for

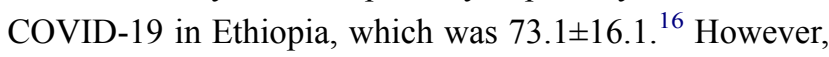
the study findings were below the ReadyScore cutoff point for better prepared ( $>80 \%$ ) which implies that much work is expected from the country as well as from the local government. ${ }^{13}$ As most health centers operate on tight budgets, they may not have the financial reserves to prepare well for an emergency like the COVID-19 pandemic. $^{20}$
In the current study, only one in five health centers was prepared for the pandemic and the rest were found within the "work to do" category of the preparedness ReadyScore. It is supported by the national study which stated that there is a disparity in the levels of preparedness. ${ }^{16}$ This might be due to differences in settings in which urban health centers prepared better than the rural health centers due to fear of exposure. ${ }^{22}$

The WHO interim guidance developed five IPC strategies needed to prevent or reduce the transmission of COVID-19 in healthcare facilities. These are screening and triage, applying standard precautions for all patients, implementing additional precautions, implementing administrative controls, and implementing environmental and engineering controls. The guidance stated that screening all persons at the first point of contact with the healthcare facility is critical to allow for early recognition and 
immediate isolation. ${ }^{23}$ But in this study, only $56 \%$ of the health centers had a well-equipped triage.

Effective use of PPE is considered as one of the methods for preventing the spread of COVID-19 to and from healthcare providers and patients. In this study, only $21.7 \%$ of health centers have an adequate amount of PPE at the store. It was supported by studies conducted on the availability of PPE in South America, and Addis Ababa in which only $21.8 \%$ and $23 \%$ of the hospitals have an adequate amount of PPE, respectively. ${ }^{24,25}$ Further, a study from the hospitals of North Shewa zone, Ethiopia reported that the availability of PPE was $29.5 \%{ }^{26}$ A study from Nigeria reported that only $34.4 \%$ of health professionals used face masks while consulting patients with respiratory symptoms. ${ }^{27}$ This showed that healthcare systems had shocked by a shortage of PPE. This might be because the government gives high priority to COVID-19 treatment centers.

\section{Conclusion}

In conclusion, the preparedness status of the majority of health centers in South Wollo Zone was within the "work to do" group. Therefore, the local government and other concerned bodies like sponsoring organizations should monitor and support health centers to increase their preparedness and to build their capacity.

\section{Abbreviation}

COVID-19, coronavirus disease 2019; HCW, healthcare worker; IPC, infection prevention and control; JEE, Joint External Evaluation; PPE, personal protective equipment; WHO, World Health Organization.

\section{Data Sharing Statement}

All the required data has been included in the manuscript.

\section{Consent for Publication}

Consent for publication is secured from study participants.

\section{Acknowledgments}

We would like to thank data collectors, the managers of Health Centers as well as South Wollo zone health office for their cooperation.

\section{Author Contributions}

FY, AA, and FT have participated in the conception, study design, execution, data acquisition, investigation, supervision, formal analysis, interpretation, writing the original draft, substantially reviewing, and editing the manuscript. And all authors have reviewed and agreed on all versions of the article before submission and during revision; agreed on the journal to which the article will be submitted; and agree to take responsibility and be accountable for the contents of the article.

\section{Funding}

There is no funding to report.

\section{Disclosure}

The authors declared that they have no conflicts of interest for this work.

\section{References}

1. WHO. Modes of Transmission of Virus Causing COVID-19: Implications for IPC Precaution Recommendations: Scientific Brief, 27 March 2020. World Health Organization; 2020.

2. Struyf T, Deeks JJ, Dinnes J, et al. Signs and symptoms to determine if a patient presenting in primary care or hospital outpatient settings has COVID-19 disease. Cochrane Database Syst Rev. 2020;7.

3. WHO. Coronavirus Disease 2019 (COVID-19) Strategic Preparedness and Response Plan: Accelerating Readiness in the Eastern Mediterranean Region: February 2020. World Health Organization. Regional Office for the Eastern Mediterranean; 2020.

4. World health data platform explore WHO's key data tools, data sets and databases. Available from: https://www.who.int/data. Accessed October 31, 2020.

5. Africa WROf. WHO Ramps Up Preparedness for Novel Coronavirus in the African Region. 2020.

6. Ting DSW, Carin L, Dzau V, Wong TY. Digital technology and COVID-19. Nat Med. 2020;26(4):459-461. doi:10.1038/s41591020-0824-5

7. Sohrabi C, Alsafi Z, O'Neill N, et al. World Health Organization declares global emergency: a review of the 2019 novel coronavirus (COVID-19). Int J Surg. 2020;76:71-76

8. Jee Y. WHO international health regulations emergency committee for the COVID-19 outbreak. Epidemiol Health. 2020;42:e2020013. doi:10.4178/epih.e2020013

9. Gilbert M, Pullano G, Pinotti F, et al. Preparedness and vulnerability of African countries against importations of COVID-19: a modelling study. Lancet. 2020;395(10227):871-877. doi:10.1016/S01406736(20)30411-6

10. WHO. Critical Preparedness, Readiness and Response Actions for COVID-19: Interim Guidance, 22 March 2020. World Health Organization; 2020.

11. Ethiopia MoH. Infection prevention and control interim protocol for COVID-19 in health care settings in Ethiopia. April, 2020. Available from: https://www.ephi.gov.et/images/EPHI_PHEOC_COVID-19_ IPC_Interim_Guideline\%20_Eng.pdf. Accessed January 5, 2021.

12. Baye K. COVID-19 Prevention Measures in Ethiopia: Current Realities and Prospects. Vol. 141. Intl Food Policy Res Inst; 2020.

13. ReadyScore/resolve to save lives. Available from: https://resolvetosa velives.org/prevent-epidemics/readyscore. Accessed October 29, 2020.

14. WHO. Joint External Evaluation of IHR Core Capacities of the Federal Democratic Republic of Ethiopia: Mission Report, March 2016. World Health Organization; 2017. 
15. Ethiopia overview/prevent epidemics. Available from: https://preven tepidemics.org/countries/eth/?section=data\#country-strengths-gaps. Accessed September 23, 2020.

16. Abebe Y, Beshir IA, Tsegaye ZT, et al. Health system adaptability at primary level care in the time of COIVD-19: experiences from Ethiopia. 2020.

17. Sharma SK, Sharma N. Hospital preparedness and resilience in public health emergencies at district hospitals and community health centres. J Health Manag. 2020;22(2):146-156. doi:10.1177/ 0972063420935539

18. Centers for Disease Control and Prevention. Facility Readiness Assessment for Coronavirus Disease 2019 (COVID-19). Infection Prevention and Control Considerations in Non-US Healthcare Settings. CDC. 2020. Available from: https://www.cdc.gov/corona virus/2019-ncov/downloads/healthcare-facility-readiness-assessment. pdf. Accessed February 25, 2021.

19. WHO. Hospital Readiness Checklist for COVID-19 Interim Version February 24 2020. World Health Organization. Regional Office for Europe; 2020.

20. Burse N, Thompson E, Monger M. The role of public health in COVID-19 emergency response efforts from a rural health perspective. PCD Staff. 17:E70. 2020.

21. European Centre for Disease Prevention and Control. Infection prevention and control and preparedness for COVID-19 in healthcare settings - fifth update. 6 October 2020. ECDC. Stockholm; 2020. Available from: https:/www.ecdc.europa.eu/sites/default/files/docu ments/Infection-prevention-and-control-in-healthcare-settingsCOVID-19_5th_update.pdf. Accessed February 25, 2021.
22. Blanchet K, Nam SL, Ramalingam B, Pozo-Martin F. Governance and capacity to manage resilience of health systems: towards a new conceptual framework. Int J Health Policy Manag. 2017;6(8):431. doi:10.15171/ijhpm.2017.36

23. WHO. Infection Prevention and Control Guidance for Long-Term Care Facilities in the Context of COVID-19: Interim Guidance, 21 March 2020. World Health Organization; 2020.

24. Deressa W, Worku A, Abebe W, Gizaw M, Amogne W. Availability of personal protective equipment and satisfaction of healthcare professionals during COVID-19 pandemic in Ethiopia. medRxiv. 2020.

25. Martin-Delgado J, Viteri E, Mula A, et al. Availability of personal protective equipment and diagnostic and treatment facilities for healthcare workers involved in COVID-19 care: a cross-sectional study in Brazil, Colombia, and Ecuador. PLoS One. 2020;15(11): e0242185. doi:10.1371/journal.pone.0242185

26. Mulu GB, Kebede WM, Worku SA, Mittiku YM, Ayelign B. Preparedness and responses of healthcare providers to combat the spread of COVID-19 among North Shewa Zone Hospitals, Amhara, Ethiopia, 2020. Infect Drug Resist. 2020;13:3171.

27. Umar SS, Muhammad BO, Zaharadeen SB. Preparedness of Nigerian health institutions toward managing lassa fever epidemic and Covid-19 pandemic. Niger J Med. 2020;29(2):303. doi:10.4103/ NJM.NJM 7120
Risk Management and Healthcare Policy

\section{Publish your work in this journal}

Risk Management and Healthcare Policy is an international, peerreviewed, open access journal focusing on all aspects of public health, policy, and preventative measures to promote good health and improve morbidity and mortality in the population. The journal welcomes submitted papers covering original research, basic science, clinical \& epidemiological studies, reviews and evaluations,

\section{Dovepress}

guidelines, expert opinion and commentary, case reports and extended reports. The manuscript management system is completely online and includes a very quick and fair peer-review system, which is all easy to use. Visit http://www.dovepress.com/testimonials.php to read real quotes from published authors. 